\title{
Delineation of Ground Water Potential Zone using Remote Sensing, GIS and GPS, in Mauranipur Block, Jhansi District (UP), India
}

\author{
Shivam Pandey ${ }^{1}$, Sashikant Tripathi ${ }^{1}$ and Arjun Singh ${ }^{2 *}$ \\ ${ }^{1}$ (Department of Physical Science), MGCGV Chitrakoot, Satna, M.P., India \\ ${ }^{2}$ Groundwater Resources Division, RSAC Lucknow U.P., India \\ *Corresponding author
}

\section{A B S T R A C T}

\section{Keywords \\ Groundwater, potential zone, ArcGIS, satellite data}

\section{Article Info}

Accepted:

18 May 2020

Available Online:

10 June 2020
Groundwater is an important resource contributing significantly in total annual supply. However, over exploitation has depleted groundwater availability considerably and also led to land subsidence at some places. Assessing the potential zone of groundwater recharge is extremely important for the protection of water quality and the management of groundwater systems. Groundwater potential zones are demarked with the help of remote sensing and Geographic Information System (GIS) techniques. In this study a standard methodology is proposed to determine groundwater potential using integration of RS \& GIS technique. The composite map is generated using GIS tools. The accurate information to obtain the parameters that can be considered for identifying the groundwater potential zone such as geology, slope, drainage density, geomorphic units and lineament density are generated using the satellite data and survey of India (SOI) toposheets of scale 1:50000. It is then integrated with weighted overlay in ArcGIS. Suitable ranks are assigned for each category of these parameters. For the various geomorphic units, weight factors are decided based on their capability to store groundwater. This procedure is repeated for all the other layers and resultant layers are reclassified. The groundwater potential zones are classified into five categories like very poor, poor, moderate, good \& excellent. The use of suggested methodology is demonstrated for a selected study area in Mauranipur Block Jhansi district of UP. This groundwater potential information will be useful for effective identification of suitable locations for extraction of water.

\section{Introduction}

Groundwater storage potential here refers to the total amount of permanent storage that exists in the aquifers. Groundwater storage potential is the function of the porosities of the rocks and amount of open space in rocks that could store water. Groundwater is the water present beneath Earth's surface in soil pore spaces and in the fractures of rock formations. A unit of rock or an unconsolidated deposit is called an aquifer when it can yield a usable quantity of water. The depth at which soil pore spaces or fractures and voids in rock become completely saturated with water is called the water table.

Groundwater is recharged from and eventually flows to the surface naturally; natural discharge often occurs at springs and seeps, and can form oases or wetlands. 
Groundwater is also often withdrawn for agricultural, municipal, and industrial use by constructing and operating extraction wells. The study of the distribution and movement of groundwater is hydrogeology, also called groundwater hydrology.

The available water resources are inadequate to cater to the needs of water requirement for various purposes owing to increase in population growth. The demand for water has increase over years, which needs the development of quantity and quality of water. In arid and semiarid areas, surface water is limited in extent and hence pressure on groundwater utilization. Development of groundwater and its proper management is necessary specially in hard rock areas. The interpretation of satellite data in conjunction with sufficient ground truth information makes it possible to identify and outline various ground features (such as geological structures, geomorphic features and their hydraulic characters), that may serve as direct or indirect indicators of the presence of groundwater. The geomorphological conditions are essential prerequisite in understanding water bearing characteristics of hard rooks. Sufficiently thick weathered zone forms groundwater storage in hard rock areas but often may not provide regular supply of groundwater. Remote Sensing and GIS (Geographic Information System) techniques permit rapid and cost effective natural resource survey and management. Moreover, the integrated GIS analysis serves as vital tool in generating water resources development plan of an area (Sharaf et al., 1998).

Remote sensing is a technique in which information can be obtained about any feature without actually coming into its physical contact. It has become one of the important tools in water resource study, development and management. Through remote sensing technique, we can easily get information about geomorphology, geology, soil types, and vegetation area and drainage pattern of the locations.

The Geographic Information System also known as GIS is a newly emerging discipline of applied sciences. GIS is concerned with the collection or capture of spatial data by such methods as satellite remotely sensed images, aerial photographs, Global Positioning System (GPS), Light Detection and Ranging (LIDAR) maps and surveys of people. GIS is advanced version of Information Technology (IT) and Information Communication Technology (ICT) which provide quick data/information with digital maps. It provides a unique opportunity for integration of data and information on natural and human resources, and environment which in turn helps developing decision support system for planners, administrators, decision makers and researchers of physical, biological, chemical and social sciences. A thorough understanding of GIS is therefore, necessary for effective utilization of natural resources and in efficient administration, planning, monitoring and decision making.

In view of above potentiality of remote sensing, GIS and resistivity survey, which helps in detecting quality and quantity of water, a study has been under taken in part of Mauranipur block, Jhansi district, Uttar Pradesh, India .The objective of this study is to derive groundwater potential and feasibility for the tube wells. The overlay analysis of land use map with the groundwater potential map may help in highlighting the disparities related to the land use practices in the area.

The main objectives of the study area were the study plans to carry out a detailed enquiry into the existing scenario in regard to the availability of groundwater (for various domestic and other activities) in Mauranipur Block of Jhansi District and to formulate an 
action plan for development and management of this vital natural resource The main objectives of the study are, to study the present status of the potential recharge zones with respect to the geology, permeability, soil depth, drainage intensity, soil texture, water holding capacity and physiographic conditions of the area. And to assess the pattern of availability and use of water resources for domestic purposes in the city by using both conventional and geo informatics based techniques like Remote Sensing, GIS, GPS, etc. To explore the potential for rainwater harvesting in the GMC area, identifying probable sites, suitable types, appropriate methods and management techniques. To identify Ground water potential zone map through integration of various thematic maps with GIS techniques and ground water level depth data. And also to identify suitable Rainwater Harvesting structure for specific location using ground water potential zone categories.

\section{Materials and Methods}

To fulfill the objectives and test the hypothesis of the study, the data have been collected from both primary and secondary sources. The collected data were analysed and represented in the form of maps, tables, charts, figures, etc. Geoinformatic techniques like, Remote Sensing, GIS and GPS were also used to achieve the objectives and attain the necessary results. During the course of the investigation, visual interpretation as well as digital image processing of remote sensing data was carried out along with the conventional field methods. The entire process of investigation can broadly be divided into three major activities,

Field data collection through conventional methods.

Satellite data analysis and interpretation using remote sensing techniques.
Integration of remote sensing and conventional databases with the help of GIS to develop a decision support system.

The research design has the following major components,

Selection of the study area and its delimitation.

Collection of data, Primary and Secondary.

Site selection for observation of groundwater levels.

Database creation, analysis and integration.

Presentation and interpretation of data.

Database and data used are

Resourcesat (LISS III) Multispectral data and Cartosat -1 (PAN data).

Survey of India toposheets (1:50,000 scale).

Field observations

Field observations, Preparing and integrating different thematic layers viz., hydrogeomorphlogy, slope, drainage density, lineament density, DEM, lithology, soil, land use/land cover

The database include both primary data collected from the field as well as a variety of collateral data collected from various government departments, academic institutions and other published documents and reports. Primary data on various parameters pertaining to the study area have been collected based on field surveys using a questionnaire (Annexure - I) specially designed for the purpose and making field measurements on selected geohydrological parameters like groundwater level in wells, volume of surface water bodies, etc. The number of households surveyed in the study area was decided based on the total number of households in a particular ward. To acquire the groundwater level in different parts of the study area, water levels of dug wells were also taken. 
Lithology, lineament, landform, slope, vegetation, groundwater recharge and discharge are common features used for many groundwater resource assessments in hard rock areas. Remote sensing data provide accurate spatial information and are cost- effective compared with conventional methods of hydrogeological surveys.

Digital enhancement of satellite data improves maximum extraction of information useful for groundwater studies. GIS techniques facilitate integration and analysis of large volumes of data, whereas field studies help to further validate results. Integrating all these approaches offers a better understanding of features controlling groundwater occurrence in hard rock aquifers.

\section{Application of remote sensing in groundwater exploration}

Remote sensing and GIS methods permit rapid and cost effective natural resource survey and management. Moreover, remotely sensed data serve as vital tool in groundwater prospecting. The remote sensing data helps in fairly accurate hydro geomorphological analysis and identification and delineation of land features with sufficient ground data, hydrological characteristics of geomorphological features can be deciphered. Groundwater occurrence being subsurface phenomenon, its identification and location is based on indirect analysis of some directly observed terrain features like geological and geomorphic features and their hydrologic characters. Satellite remote sensing provides an opportunity for better observation and more systematic analysis of various geomorphic units, lineament features, following the integration with the help of
Geographical Information System to demarcate the groundwater potential zones.

Therefore, an integrated approach, including studies of Lithology, Hydrogeomorphology and lineament, has been taken up, using remote sensing and GIS techniques, for a proper assessment of groundwater potential zones in the study area.

\section{Results and Discussion}

Delineating the Ground water potential zones in Mauranipur Block of Jhansi District, UttarPradesh using Remote Sensing, GPS, and GIS techniques. It's found efficient to minimize the time, labour and money for sustainable water resource management. Ground water Potential zone map has been categories into four category poor, moderate, very Good, limited.

According to this category prepared Rainwater Harvesting structure map which will be helpful to remove water scarcity problem. In very Good category of Groundwater potential zone and according to Hydro- Geomorphology palaeo feature and younger alluvial we can establish Check Dam and Recharge Pit structures. and in moderate category and nearby Hydro-Geomorphology features drainage, ravines we can established Desilting tank and invert well and last poor category and nearby Water bodies we can established dug well recharge structure. This artificial recharge structure will be helpful to recharge of Groundwater.

The main source of water in mauranipur block is river. In mauranipur block most of the region having limited groundwater that also mentioned in the below Table \&map. 
Table.1 Source of water

\begin{tabular}{|c|c|}
\hline Groundwater Prospects Zone & Area (in Hect) \\
\hline Limited Zone & 29576.775 \\
\hline Moderate Zone & 68.85 \\
\hline Poor Zone & 24898.34 \\
\hline Very Good Zone & 205.952 \\
\hline
\end{tabular}

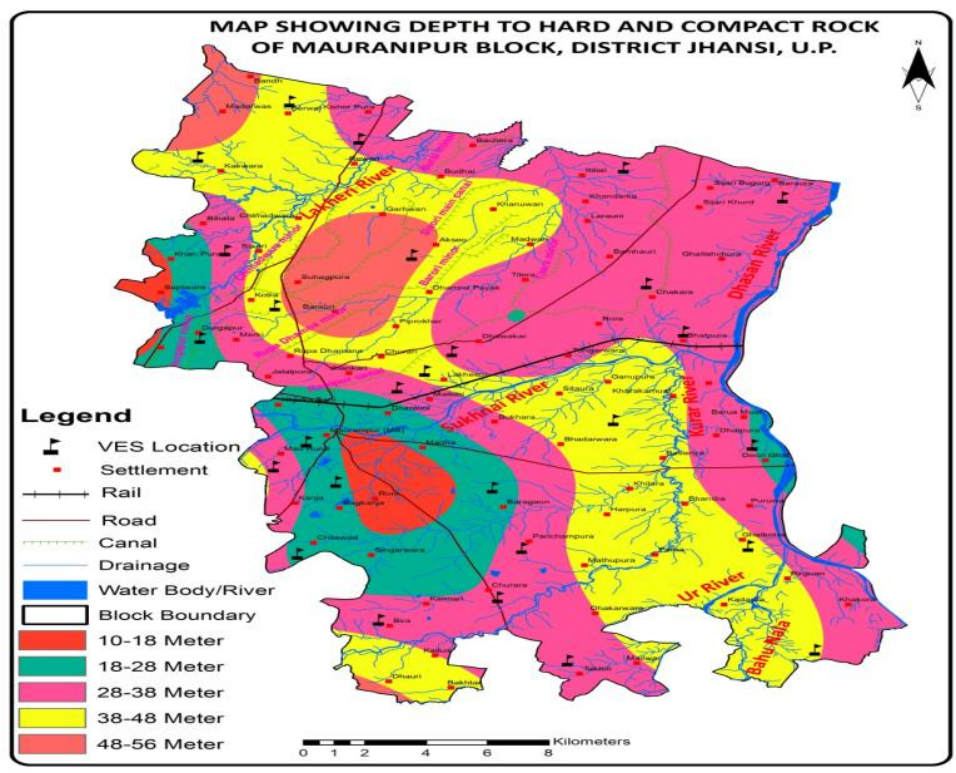

Fig.1

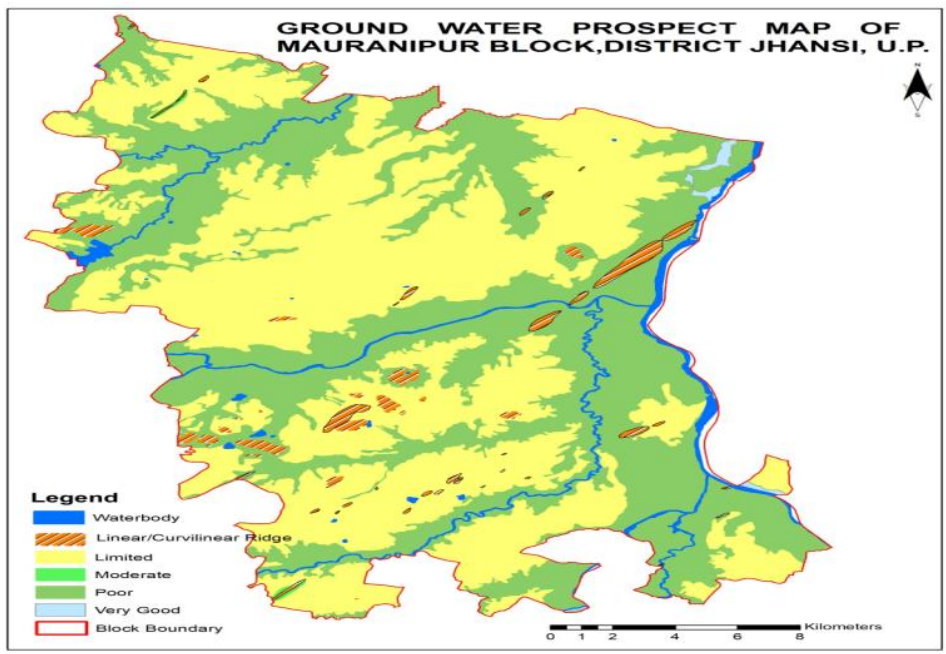

Fig.2 
MAP SHOWING LOCATION MAP OF MAURANIPUR BLOCK, DISTRICT JHANSI, U.P.

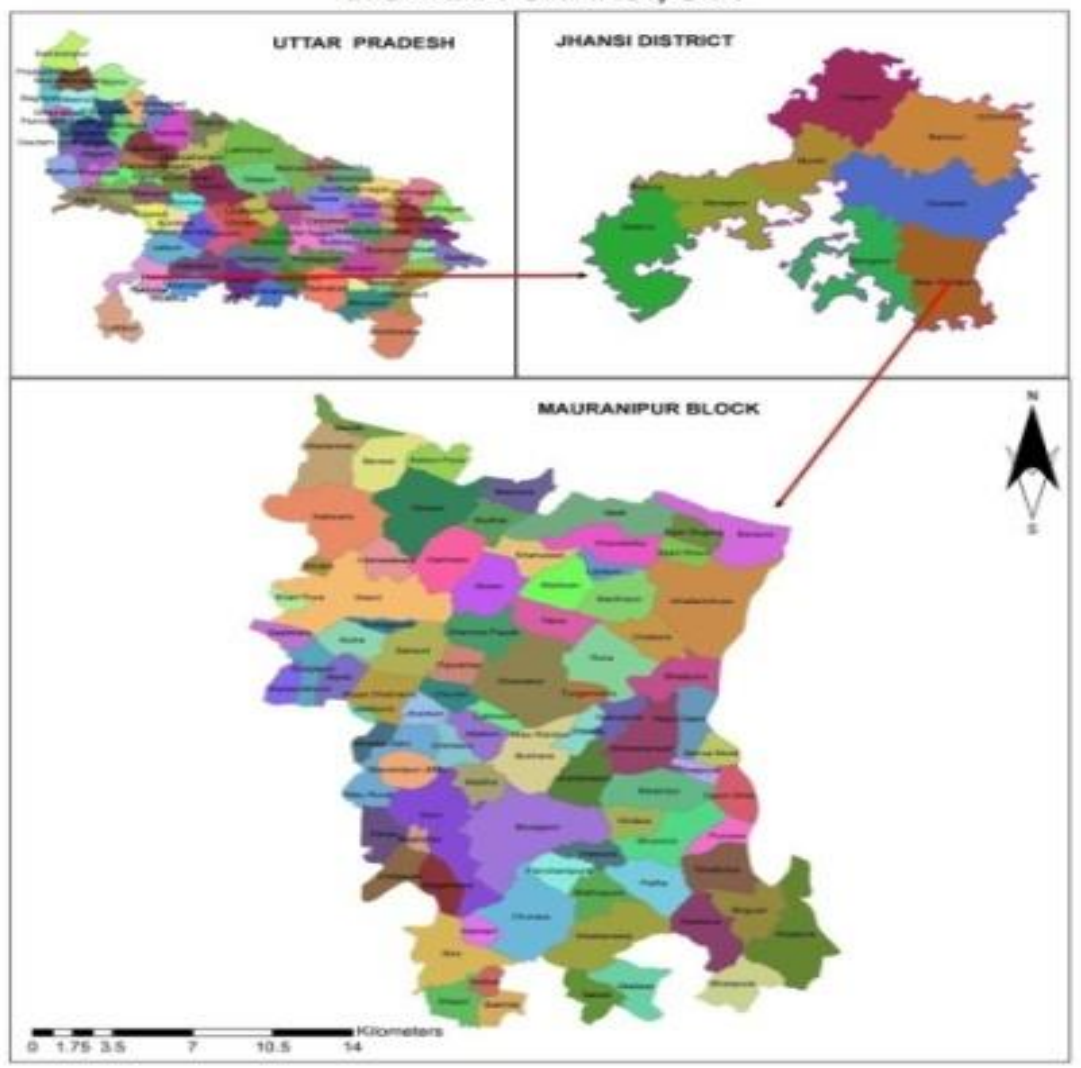

Fig.3

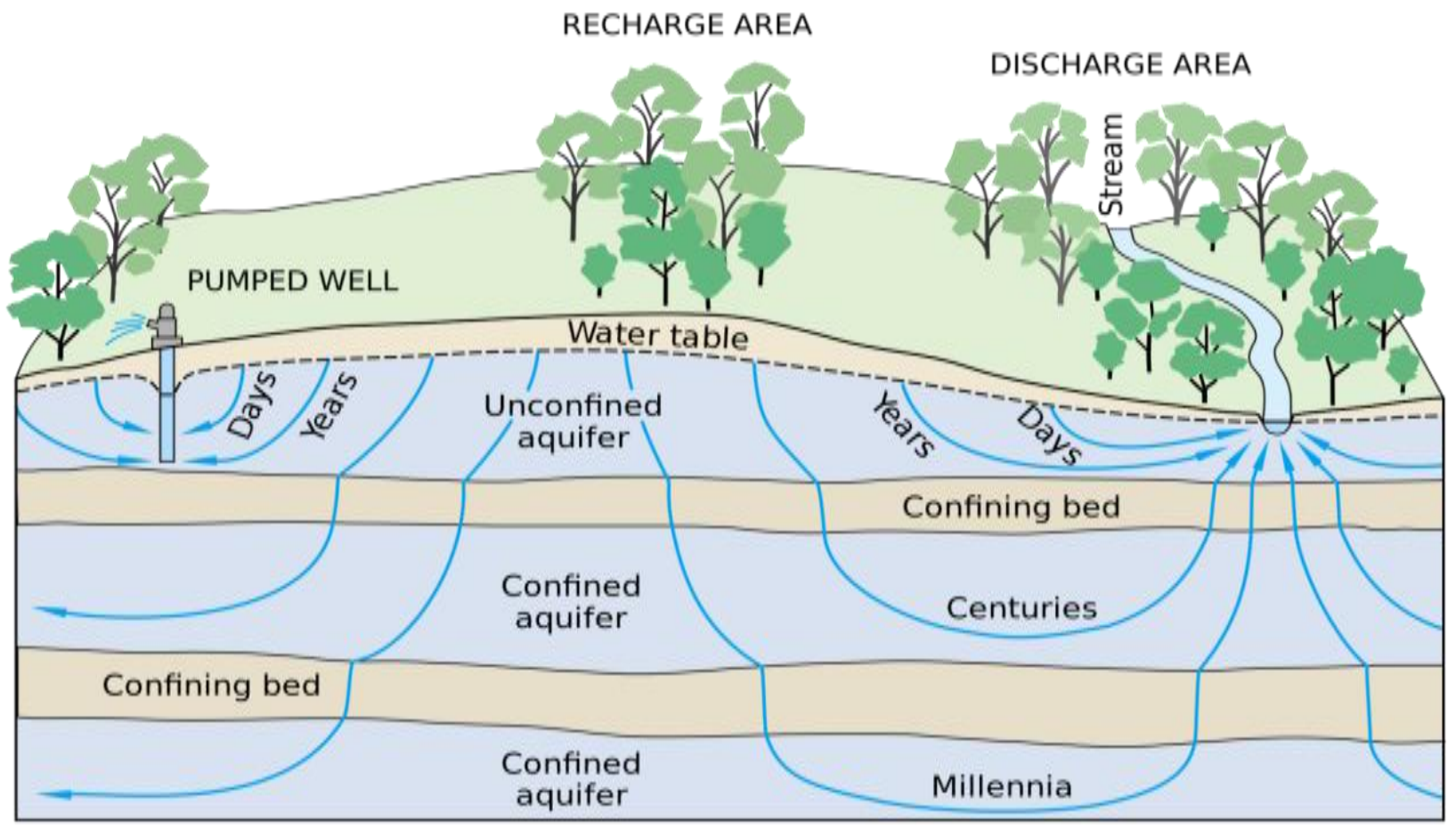

Fig.4 Categories of Aquifer 

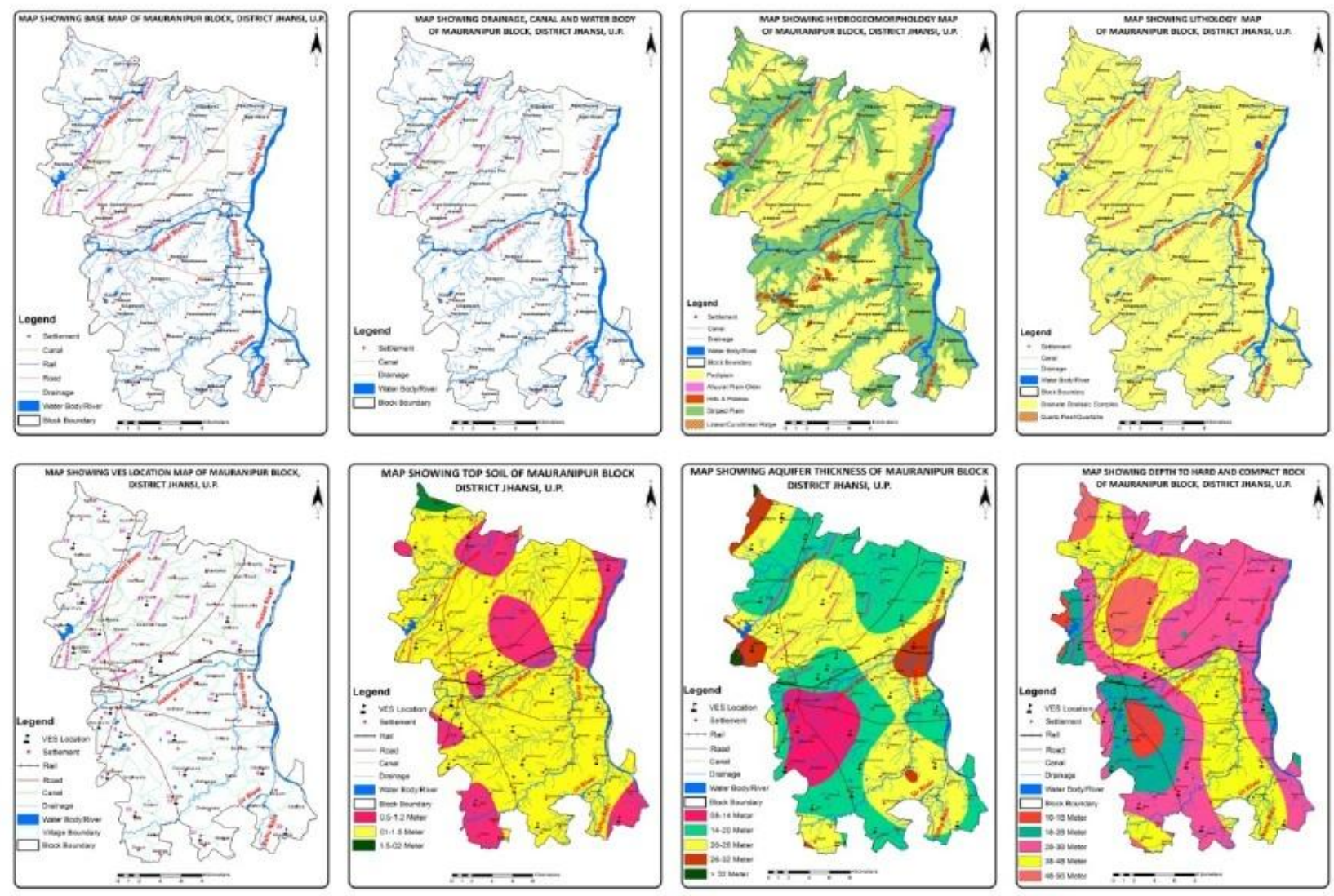

Fig.5

Baraura village having more groundwater potential and the village like Churari, Piprokhar, Jalalpura, kaimari are having limited potential of groundwater. Village like Dhaipura, Baruamauf, Ghatkotra are poor potential zone of groundwater.

\section{References}

Australia, and National Water Commission, 2012, Groundwater Essentials. Canberra, ACT.: National Water Commission.

Cardimona, Steve. 2002. Electrical Resistivity Techniques for Subsurfac Investigation. Department of Geophysics, University of Missouri Rolla-Mo.
Chapman, Deborah, 1996, Water Quality Assessments: A Guide to the Use of Biota, Sediments and Water Environmental Monitoring. 2. ed. London:E \& FN Spon.

Chidambaram, S., and others,2013, "Identification of Groundwater Potential Zone by Using GIS and Electrical Resistivity Techniques in and around the Wellington Reservoir, Cuddalore District, Tamilnadu, India. European Scientific Journal, ESJ9, no. 17.

Dwivedi, Arun Kumar, and SudhirSingh Bhadauria, 2006, Domestic Rooftop Water Harvesting-a Case Study. Ground Water4 : 14-0. 


\section{How to cite this article:}

Shivam Pandey, Sashikant Tripathi and Arjun Singh. 2020. Delineation of Ground Water Potential Zone using Remote Sensing, GIS and GPS, in Mauranipur Block, Jhansi District (UP), India. Int.J.Curr.Microbiol.App.Sci. 9(06): 2138-2145.

doi: https://doi.org/10.20546/ijcmas.2020.906.261 